\title{
Desempenho fisiológico de sementes de gergelim submetidas a estresse hídrico em diferentes temperaturas
}

\section{Physiological performance of sesame seeds under the water stress at different temperatures}

\author{
Dayana Silva de Medeiros ${ }^{1 *}$; Edna Ursulino Alves ${ }^{2}$; Daniela Vieira \\ dos Anjos Sena ${ }^{1}$; Edna de Oliveira Silva ${ }^{1}$; Luciana Rodrigues de Araújo ${ }^{3}$
}

\section{Resumo}

O gergelim (Sesamum indicum L.) tem grande potencial econômico, devido às possibilidades de exploração tanto no mercado nacional como internacional, o qual pode ser cultivado em segunda época ou safrinha quando está sujeito a condições climáticas menos favoráveis durante a semeadura e emergência, como o déficit hídrico. Diante disso objetivou-se avaliar o efeito do estresse hídrico induzido por soluções de polietileno glicol (PEG 6000) em diferentes temperaturas no desempenho fisiológico de sementes de gergelim. No trabalho utilizaram-se soluções de PEG $6000 \mathrm{com}$ diferentes potenciais osmóticos $(0,0$ controle $)$ e $(-0,2 ;-0,4 ;-0,6$ e $-0,8 ;-1,0-1,2$ e $-1,4 \mathrm{MPa})$ nas temperaturas de 25,30 e $35^{\circ} \mathrm{C}$. Na determinação do efeito dos tratamentos avaliou-se a germinação e o vigor (primeira contagem, comprimento da raiz primária e parte aérea), em delineamento experimental inteiramente ao acaso, com quatro repetições. O desempenho fisiológico das sementes de gergelim é afetado pelo estresse hídrico, com reduções significativas na germinação e no vigor, sendo que a temperatura de 30 ${ }^{\circ} \mathrm{C}$ favoreceu o desempenho germinativo em potenciais hídricos menos restritivos.

Palavras-chave: Sesamum indicum L., oleaginosa, germinação, vigor

\begin{abstract}
Sesame (Sesamum indicum L.) shows great economic potential because it can be explored by the national as well as the international market. It can be grown in the second season when it is subject to less favorable weather conditions such as drought during the sowing and emergence. Given this the objective was to evaluate the effect of water stress induced by polyethylene glycol solutions (PEG 6000 ) at different temperatures in order to asses the physiological quality of sesame seeds. In this work, were used PEG 6000 with different osmotic potentials $(0.0$ control) and $(-0.2,-0.4,-0.6,-0.8,-1.0$ $-1,2$ and $-1.4 \mathrm{MPa}$ ) at temperatures of 25,30 and $35^{\circ} \mathrm{C}$. For determine the effect of the treatments it was evaluated seed germination and vigor (first count and length of the primary root and shoot), in a completely randomized, with four replications. The sesame seeds are affected by water stress, with significant reductions in germination and vigor. A temperature of $30^{\circ} \mathrm{C}$ favored the germination performance in less restrictive water potentials.
\end{abstract}

Key words: Sesamum indicum, oil seed, germination, vigor

\footnotetext{
1 Discentes do Curso de Doutorado do Programa de Pós-Graduação em Agronomia, Universidade Federal da Paraíba, Centro de Ciências Agrárias, UFPB/CCA, Areia, PB. E-mail: anymedeiros@gmail.com; danielasenas@hotmail.com; ednaagronomia@ yahoo.com.br

2 Prof $^{\mathrm{a}}$, Dept ${ }^{\mathrm{o}}$ de Fitotecnia, UFPB/CCA, Areia, PB. E-mail: ednaursulino@cca.ufpb.br

3 Eng ${ }^{\mathrm{a}}$ Agr ${ }^{\mathrm{a}}$, Programa Nacional de Pós-Doutorado, PNPD, UFPB/CCA, Areia, PB. E-mail: 1raraujo1@yahoo.com.br

* Autor para correspondência
} 
O gergelim ou sésamo (Sesamum indicum L.), pertencente à família Pedaliaceae é uma planta adaptada aos climas tropical e subtropical, facilmente cultivada em regiões secas (FAZELI; GHORBANLI; NIKNAM, 2006) e considerada uma das oleaginosas mais antigas e conhecidas, a qual tem alto conteúdo de ácidos graxos insaturados bastante usados na indústria alimentícia, principalmente na panificação, produção de biscoitos, doces e na fabricação de margarina; além disso, seu óleo participa na produção de cosméticos, perfumes, remédios, lubrificantes, sabão, tintas e inseticidas (BELTRÃO et al., 2010).

O cultivo do gergelim, por ocorrer em segunda época ou safrinha está sujeito às condições climáticas menos favoráveis durante a semeadura e emergência, de forma que os estudos de germinação de suas sementes em condições induzidas de estresse hídrico são de fundamental importância, uma vez que a água disponível para as plantas é o fator que mais limita o potencial de produção agrícola em regiões semiáridas (STONE et al., 2001).

A germinação é uma das fases mais críticas do ciclo de vida das plantas porque a absorção de água é o fator responsável pelo início da mesma, a qual está envolvida direta e indiretamente nas demais etapas do metabolismo germinativo, uma vez que a participação da água é decisiva nas reações enzimáticas, na solubilização e transporte de metabólitos, como reagente na digestão hidrolítica de tecidos de reserva da semente (MARCOS FILHO, 2005). Os potenciais osmóticos muito negativos retardam e diminuem a germinação (MORTELE; SCAPIM; LUCCA, 2008), especialmente no começo da embebição porque inviabilizam a sequência dos eventos germinativos da semente durante a absorção de água.

Em condições de laboratório são realizados estudos com soluções aquosas de diferentes potenciais osmóticos para umedecer o substrato de germinação, procurando simular as condições de estresse hídrico no solo (TAIZ; ZEIGER, 2013), que geralmente atuam diminuindo a velocidade e a porcentagem de germinação das sementes. Para cada espécie existe um valor de potencial hídrico no solo, abaixo do qual a germinação não ocorre (ADEGBUYI; COOPER; DON, 1981), sendo verificado também a existência de grande variação de resposta ao estresse entre as espécies, desde aquelas muito sensíveis até as mais tolerantes (BEWLEY; BLACK, 1994).

As técnicas utilizadas em laboratório para simular condições de baixa umidade no substrato têm sido com soluções aquosas com diferentes potenciais osmóticos, podendo provocar atraso no processo germinativo ou diminuição na porcentagem final de germinação. Na simulação de estresse hídrico, diversos compostos químicos têm sido utilizados, dentre eles o polietileno glicol (PEG 6000) com a finalidade de simular condições padronizadas do mesmo (PEREIRA et al., 2012).

A temperatura em que ocorre a germinação das sementes é outro fator que tem influência sobre o referido processo, tanto no aspecto da germinação total como da velocidade em que a mesma ocorre, uma vez que interfere na dinâmica da absorção de água, nos limites e velocidade das reações bioquímicas, além dos processos fisiológicos que determinam todo o processo germinativo (MARCOS FILHO, 2005).

Algumas pesquisas simulando o efeito do estresse hídrico na germinação e vigor de sementes de diferentes espécies têm sido desenvolvidas, a exemplo daquelas com sementes de soja (Glycine $\max$ L.) (COLETE et al., 2007), cujos potenciais abaixo de $-0,6$ e - $0,9 \mathrm{MPa}$ foram considerados críticos à germinação. Por outro lado, as sementes de girassol (Helianthus annuus L.) demostraram resistência ao estresse hídrico, cujo limite máximo de tolerância foi de -0,4 MPa de PEG (CARNEIRO et al., 2011).

Desta forma, neste trabalho o objetivo foi avaliar o efeito do estresse hídrico induzido por soluções de polietileno glicol em diferentes temperaturas no desempenho fisiológico de sementes de gergelim. 
O trabalho foi conduzido no Laboratório de Análise de Sementes pertencente ao Departamento de Fitotecnia e Ciências Ambientais do Centro de Ciências Agrárias, da Universidade Federal da Paraíba, em Areia - PB. As sementes utilizadas foram de gergelim, da cultivar BRS Seda provenientes da EMBRAPA Algodão - PB, submetidas à germinação em diferentes potenciais osmóticos, simulando situações de estresse hídrico.

Para avaliação da germinação foram utilizadas as soluções de PEG 6000 com diferentes potenciais osmóticos ( 0,0 (controle); $-0,2 ;-0,4 ;-0,6$ e $-0,8$; $-1,0-1,2$ e $-1,4 \mathrm{MPa}$ ) preparadas de acordo com as especificações contidas na tabela citada por Villela, Doni Filho e Siqueira, (1991) e, as temperaturas utilizadas foram de 25,30 e $35^{\circ} \mathrm{C}$ constantes.

No teste de germinação, para cada tratamento utilizou-se 200 sementes, divididas em quatro repetições de 50, as quais foram distribuídas sobre duas folhas de papel toalha, cobertas com uma terceira e organizadas em forma de rolo. O papel toalha foi umedecido com as soluções de PEG 6000 supracitadas na quantidade equivalente a 2,5 vezes a massa do papel não hidratado, sem adição posterior da solução, além do tratamento com água destilada e deionizada, representando a testemunha (controle). Os rolos foram acondicionados em sacos plásticos transparentes, de 0,04 $\mathrm{mm}$ de espessura, com a finalidade de evitar a perda de água por evaporação.

O teste de germinação foi conduzido em germinadores tipo Biological Oxigen Demand (B.O.D.) regulados para os regimes de temperatura citados anteriormente, com fotoperíodo de oito horas de luz e 16 de escuro, utilizando lâmpadas fluorescentes tipo luz do dia $\left(\begin{array}{llll}4 & \mathrm{x} & 20 & \mathrm{~W}\end{array}\right)$. As avaliações foram efetuadas diariamente, dos três aos seis dias após a instalação do teste, cujo critério foi o de plântulas normais, ou seja, que haviam emitido a raiz primária e a parte aérea, sendo os resultados expressos em porcentagem.

A primeira contagem foi realizada juntamente com o teste de germinação, determinando-se a porcentagem de plântulas normais no terceiro dia após a instalação do teste, com os resultados em porcentagem.

Após a contagem final do teste de germinação, as plântulas normais de cada tratamento e repetição foram medidas (raiz e parte aérea), com auxílio de uma régua graduada em centímetros, sendo os resultados expressos em cm plântula ${ }^{-1}$.

O delineamento experimental utilizado foi o inteiramente ao acaso, com os tratamentos distribuídos em esquema fatorial $8 \times 3$ (potenciais osmóticos e temperaturas), em quatro repetições. Os dados obtidos foram submetidos à análise de variância pelo teste $\mathrm{F}$, com as médias agrupadas pelo teste de Scott-Knott, a 5\% de significância, como também de regressão polinomial.

A germinação das sementes de gergelim foi afetada pelos potencias hídricos testados, tendo-se constatado no tratamento controle $(0,0)$ o maior percentual de germinação $(61,5 \%)$ na temperatura de $30{ }^{\circ} \mathrm{C}$ (Figura 1A e Tabela 1). A porcentagem de germinação reduziu significativamente a partir do potencial hídrico de $-0,2 \mathrm{MPa}$, chegando a $52 \%$ nas temperaturas de 25 e a $35^{\circ} \mathrm{C}$, constatando-se que as sementes tiveram sua capacidade germinativa mais afetada, chegando a 38\% de germinação e, a partir do potencial de $-1,0 \mathrm{MPa}$ a germinação tornou-se nula. 
Figura 1. Porcentagem (A) e primeira contagem de germinação de sementes (B) e comprimento da parte aérea (C) e raízes (D) de plântulas de gergelim submetidas ao estresse hídrico em diferentes temperaturas.

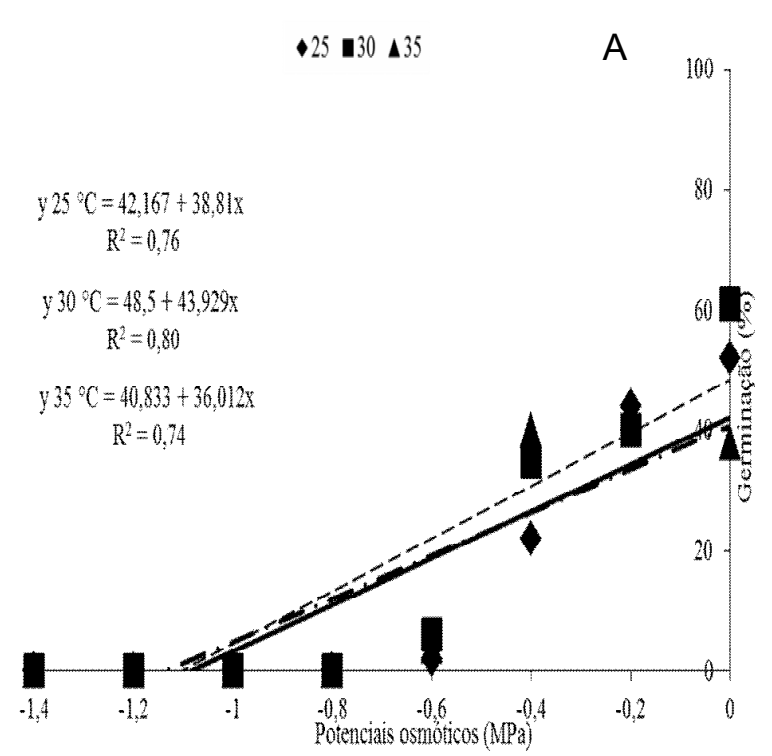

$\bullet 25 \longleftarrow 30 \Delta 35$

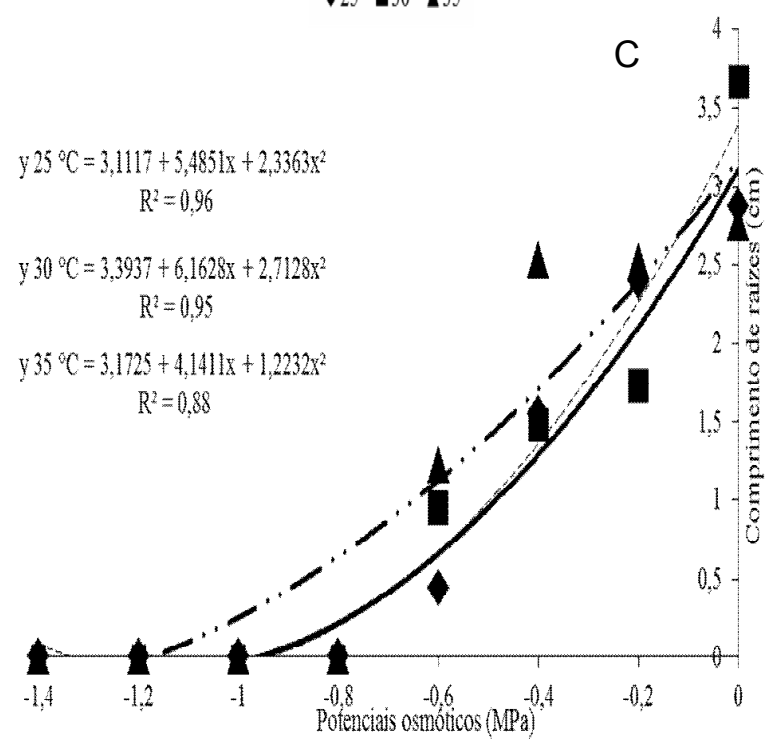

Fonte: Elaboração dos autores.

Este comportamento de redução na porcentagem de germinação quando o potencial osmótico se torna mais negativo ocorre em razão do aumento no tempo correspondente a fase III do processo de embebição, pois de acordo com o padrão trifásico proposto por Bewley e Black (1994), nesta fase ocorre a intensa absorção de água e a protrusão da raiz primária pelas sementes.
-25 \30 \35

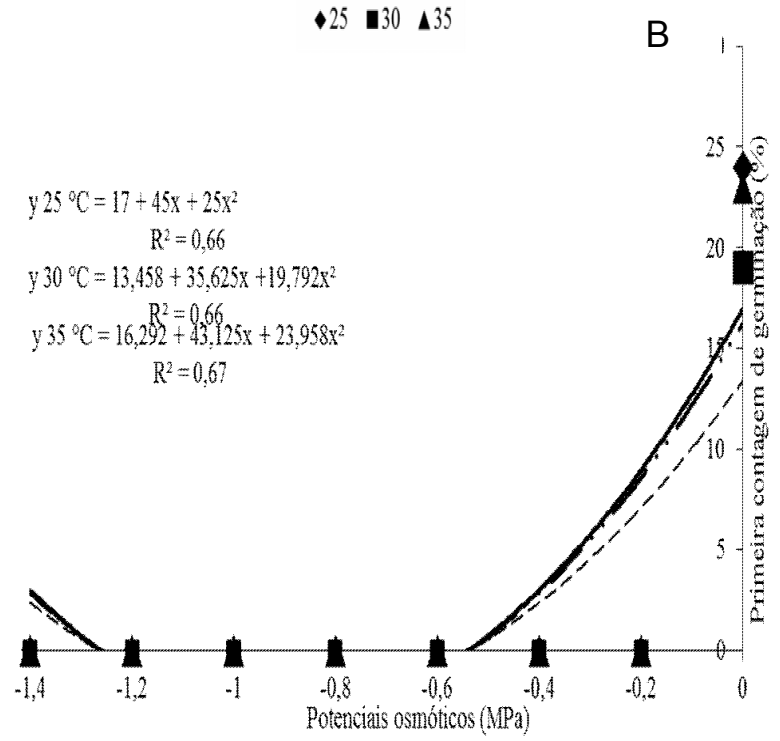

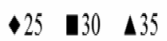

$y^{2} 5^{\circ} \mathrm{C}=2,8679+5,577 \mathrm{x}+2,5818 \mathrm{x}^{2}$ $R^{2}=0,95$

$y^{\circ} 0^{\circ} \mathrm{C}=2,2233+4,0917 \mathrm{x}+1,815 x^{2}$ $\mathrm{R}^{2}=0,98$

y $35 \mathrm{C}=2,6425+4,7917 \mathrm{x}+2,0952 \mathrm{x}^{2}$ $\mathrm{R}^{2}=0,98$

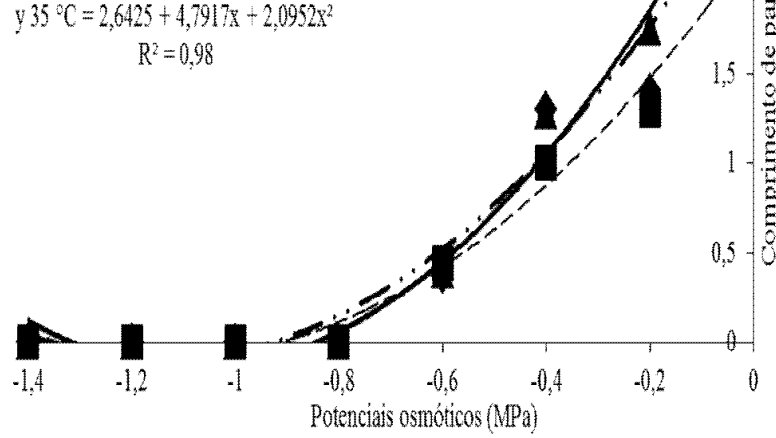

Outro fator que também pode explicar esta redução na germinação é o alto peso molecular do polietileno glicol, que não é absorvido devido à alta viscosidade, que somada à baixa taxa de difusão de $\mathrm{O}_{2}$ pode comprometer a disponibilidade de oxigênio para as sementes, durante o processo germinativo (BRACCINI et al., 1996). 
Tabela 1. Porcentagem, primeira contagem de germinação e comprimento de parte aérea e raízes de plântulas de gergelim oriundas de sementes submetidas a diferentes níveis de estresse hídrico e temperaturas.

\begin{tabular}{|c|c|c|c|c|c|c|c|c|}
\hline \multirow{3}{*}{$\begin{array}{c}\text { Temperaturas } \\
\left({ }^{\circ} \mathrm{C}\right)\end{array}$} & \multicolumn{8}{|c|}{ Potenciais osmóticos (- Mpa) } \\
\hline & \multicolumn{8}{|c|}{ Germinação (\%) } \\
\hline & 0 & 0,2 & 0,4 & 0,6 & 0,8 & 1 & 1,2 & 1,4 \\
\hline 35 & $38,00 \mathrm{c}$ & $43,00 \mathrm{a}$ & $40,00 \mathrm{a}$ & $3,50 \mathrm{a}$ & $0,00 \mathrm{a}$ & $0,00 \mathrm{a}$ & $0,00 \mathrm{a}$ & $0,00 \mathrm{a}$ \\
\hline 30 & $61,50 \mathrm{a}$ & $40,00 \mathrm{a}$ & $34,50 \mathrm{a}$ & $5,50 \mathrm{a}$ & $0,00 \mathrm{a}$ & $0,00 \mathrm{a}$ & $0,00 \mathrm{a}$ & $0,00 \mathrm{a}$ \\
\hline 25 & $52,00 \mathrm{~b}$ & $44,00 \mathrm{a}$ & $22,50 \mathrm{~b}$ & $1,50 \mathrm{a}$ & $0,00 \mathrm{a}$ & $0,00 \mathrm{a}$ & $0,00 \mathrm{a}$ & $0,00 \mathrm{a}$ \\
\hline \multicolumn{9}{|c|}{ Primeira Contagem $(\%)$} \\
\hline & 0 & 0,2 & 0,4 & 0,6 & 0,8 & 1 & 1,2 & 1,4 \\
\hline 35 & $23,00 \mathrm{a}$ & $0,00 \mathrm{a}$ & $0,00 \mathrm{a}$ & $0,00 \mathrm{a}$ & $0,00 \mathrm{a}$ & $0,00 \mathrm{a}$ & $0,00 \mathrm{a}$ & $0,00 \mathrm{a}$ \\
\hline 30 & $19,00 \mathrm{~b}$ & $0,00 \mathrm{a}$ & $0,00 \mathrm{a}$ & $0,00 \mathrm{a}$ & $0,00 \mathrm{a}$ & $0,00 \mathrm{a}$ & $0,00 \mathrm{a}$ & $0,00 \mathrm{a}$ \\
\hline 25 & $24,00 \mathrm{a}$ & $0,00 \mathrm{a}$ & $0,00 \mathrm{a}$ & $0,00 \mathrm{a}$ & $0,00 \mathrm{a}$ & $0,00 \mathrm{a}$ & $0,00 \mathrm{a}$ & $0,00 \mathrm{a}$ \\
\hline \multicolumn{9}{|c|}{ Comprimento da parte aérea $(\mathrm{cm})$} \\
\hline & 0 & 0,2 & 0,4 & 0,6 & 0,8 & 1 & 1,2 & 1,4 \\
\hline 35 & $2,65 b$ & $1,75 \mathrm{a}$ & $1,29 \mathrm{a}$ & $0,40 \mathrm{a}$ & $0,00 \mathrm{a}$ & $0,00 \mathrm{a}$ & $0,00 \mathrm{a}$ & $0,00 \mathrm{a}$ \\
\hline 30 & $2,33 \mathrm{c}$ & $1,30 \mathrm{~b}$ & $1,00 \mathrm{~b}$ & $0,44 \mathrm{a}$ & $0,00 \mathrm{a}$ & $0,00 \mathrm{a}$ & $0,00 \mathrm{a}$ & $0,00 \mathrm{a}$ \\
\hline 25 & $3,07 \mathrm{a}$ & $1,40 \mathrm{~b}$ & $1,30 \mathrm{a}$ & $0,37 \mathrm{a}$ & $0,00 \mathrm{a}$ & $0,00 \mathrm{a}$ & $0,00 \mathrm{a}$ & $0,00 \mathrm{a}$ \\
\hline \multicolumn{9}{|c|}{ Comprimento de raízes $(\mathrm{cm})$} \\
\hline & 0 & 0,2 & 0,4 & 0,6 & 0,8 & 1 & 1,2 & 1,4 \\
\hline 35 & $2,77 b$ & $2,52 \mathrm{a}$ & $2,53 a$ & $1,22 \mathrm{a}$ & $0,00 \mathrm{a}$ & $0,00 \mathrm{a}$ & $0,00 \mathrm{a}$ & $0,00 \mathrm{a}$ \\
\hline 30 & $3,66 a$ & $1,73 b$ & $1,48 b$ & $0,95 \mathrm{a}$ & $0,00 \mathrm{a}$ & $0,00 \mathrm{a}$ & $0,00 \mathrm{a}$ & $0,00 \mathrm{a}$ \\
\hline 25 & $2,88 \mathrm{~b}$ & $2,39 \mathrm{a}$ & $1,54 b$ & $0,43 b$ & $0,00 \mathrm{a}$ & $0,00 \mathrm{a}$ & $0,00 \mathrm{a}$ & $0,00 \mathrm{a}$ \\
\hline
\end{tabular}

Médias seguidas de mesma letra na coluna não diferem entre si pelo Teste de Scott-Knott a $5 \%$ de probabilidade.

Fonte: Elaboração dos autores.

Pelos resultados referentes ao vigor, determinado pela primeira contagem de germinação verificouse que as maiores porcentagens foram obtidas no tratamento controle $(0,0 \mathrm{MPa})$ com as sementes submetidas às temperaturas de 25 e $35^{\circ} \mathrm{C}$, atingindo 24 e $23 \%$ de germinação, respectivamente (Figura $1 \mathrm{~B}$ e Tabela 1). Ainda constatou-se que à medida que os potencias se tornaram mais negativos houve redução drástica na germinação, independente da temperatura utilizada, com inibição da mesma a partir do potencial de $-0,6 \mathrm{MPa}$, indicando sensibilidade das sementes de gergelim ao estresse. No entanto, através da curva de tendência observouse que mesmo sendo sensíveis a esse potencial osmótico houve um acréscimo no potencial de $-1,4$ MPa.

Dessa forma constata-se que a restrição hídrica pode reduzir a velocidade e a porcentagem de germinação à medida que o potencial osmótico se torna menor, pois influencia a velocidade dos processos metabólicos e bioquímicos, o que atrasa ou inibe a germinação das sementes, interfere na embebição e no elongamento celular do embrião (BANSAL; BHATI; SEN, 1980). A interferência negativa no vigor provavelmente deve-se à menor absorção de água pelas sementes, pois segundo Torres, Vieira e Marcos Filho (1999) o aumento da concentração osmótica provoca diminuição do gradiente hídrico no sistema solo-semente.

Com relação ao comprimento da parte aérea observou-se que as sementes submetidas à temperatura constante de $25{ }^{\circ} \mathrm{C}$ originaram plântulas de gergelim maiores quando comparadas com as de $35^{\circ} \mathrm{C}$ no tratamento controle $(0,0 \mathrm{MPa})$ (Figura 1C e Tabela 1). Nos potenciais osmóticos $-0,2$ e - - , $4 \mathrm{MPa}$ houve diferença significativa entre os mesmos, alcançando 1,75 e $1,30 \mathrm{~cm}$ a 35 e 25 ${ }^{\circ} \mathrm{C}$, respectivamente, nos demais potenciais não houve diferença significativa, independente da temperatura. 
Esses dados concordam com Taiz e Zeiger (2013), quando afirmaram que o estresse hídrico além de afetar a embebição, a velocidade e a porcentagem de germinação das sementes provoca redução no crescimento das plântulas, causada pela diminuição da expansão celular. Segundo Dell'Aquila (1992), redução no comprimento de plântulas se deve a mudanças na turgescência celular em função da diminuição da síntese de proteínas em condições de déficit hídrico.

Para o comprimento de raízes de plântulas de gergelim (Figura 1D) constatou-se que a redução do potencial hídrico da solução de PEG proporcionou diminuição no comprimento, no entanto, o maior tamanho foi alcançado no tratamento controle (0,0 MPa) na temperatura de $30{ }^{\circ} \mathrm{C}$ (Tabela 1). Provavelmente, essa diferença se deve ao fato de que as sementes vigorosas originam plântulas com maior taxa de crescimento, em função da maior capacidade de transformação do suprimento de reservas dos tecidos de armazenamento e incorporação destes pelo eixo embrionário (NAKAGAWA, 1999).

Os resultados obtidos demonstram que as sementes de gergelim são muito sensíveis quando submetidas ao estresse hídrico com solução de PEG 6000 reduzindo sua sobrevivência devido aos estreitos limites para a germinação.

O desempenho fisiológico das sementes de gergelim é afetado pelo estresse hídrico, com reduções significativas na germinação e no vigor, sendo a temperatura de $30{ }^{\circ} \mathrm{C}$ a que favorece $\mathrm{o}$ desempenho germinativo em potenciais hídricos menos restritivos.

\section{Referências}

ADEGBUYI, E.; COOPER, S. R.; DON, R. Osmotic priming of some herbage grass seed using polyethylene glycol (PEG). Seed Science and Technology, Zürich, v. 9, n. 3, p. 867-878, 1981.

BANSAL, R. P.; BHATI, P. R.; SEN, D. N. Differential specificity in water imbibition of indian arid zone seeds. Biologia Plantarum, Praha, v. 22, n. 5, p. 327-331, 1980.
BELTRÃO, N. E. M.; VALE, L. S.; MARQUES, L. F.; CARDOSO, G. D.; MARACAJA, P. B. Época relativa de plantio no consórcio mamona e gergelim. Revista Verde de Agroecologia e Desenvolvimento Sustentável, Mossoró, v. 5, n. 5, p. 6-73, 2010.

BEWLEY, J. D.; BLACK, M. Seeds: physiology of development and germination. $2^{\text {th }}$ ed. New York: Plenum Press, 1994. 445 p.

BRACCINI, A. L.; RUIZ, H. A.; BRACCINI, M. C. L.; REIS, M. S. Germinação e vigor de sementes de soja sob estresse hídrico induzido por soluções de cloreto de sódio, manitol e polietileno glicol. Revista Brasileira de Sementes, Londrina, v. 18, n. 2, p. 10-16, 1996.

CARNEIRO, M. M. L. C.; DEUNER, S.; OLIVEIRA, P. V.; TEIXEIRA, S. B.; SOUZA, C. P.; BACARIN, M. A.; MORAES, D. M. Atividade antioxidante e viabilidade de sementes de girassol após estresse hídrico e salino. Revista Brasileira de Sementes, Lavras, v. 33, n. 4, p. 752-761, 2011.

COLETE, J. C. F.; VIEIRA, R. D.; PANABIANCO, M.; DUTRA, A. S. Condutividade elétrica da solução de embebição de sementes e emergência de plântulas de soja. Revista Cientifica, Jaboticabal, v. 35, n. 1, p. 10-16, 2007.

DELL'AQUILA, A. Water uptake and protein synthesis in germinating wheat embryos under the osmotic stress of polyethylene glycol. Annals of Botany, Camberra, v. 69, n. 2, p. 167-171, 1992.

FAZELI, F.; GHORBANLI, M.; NIKNAM, V. Effect of drought on water relations, growth and solute accumulation in two sesame cultivars. Pakistan Journal of Biological Sciences, New York, v. 9, n. 9, p. 18291835, 2006.

MARCOS FILHO, J. Fisiologia de sementes de plantas cultivadas. Piracicaba: FEALQ, 2005. 425 p.

MORTELE, L. M.; SCAPIM, C. A.; LUCCA, A. B. Influência do estresse hídrico sobre o desempenho fisiológico de sementes de híbridos simples de milhopipoca. Ciência e Agrotecnologia, Lavras, v. 32, n. 6, p. 1810-1817, 2008.

NAKAGAWA, J. Testes de vigor baseados no desempenho das plântulas. In: KRZYZANOSKI, F. C.; VIEIRA, R. D.; FRANÇA NETO, J. B. (Ed.). Vigor de sementes: conceitos e testes. Londrina: ABRATES, 1999. cap. 2, p. 2-24.

PEREIRA, M. R.; MARTINS, C. M.; SOUZA, G. S. F.; MARTINS, D. Influência do estresse hídrico e salino na germinação de Urochloa decumbens e Urochloa ruziziensis. Bioscience Journal, Uberlândia, v. 28, n. 4, p. 537-545, 2012. 
STONE, L. R.; GOODRUM, D. E.; JAAFAR, M. N.; KHAN, A. K. Rooting front and water depletion depths in grain sorghum and sunflower. Agronomy Journal, Madison, v. 93, n. 5, p. 1105-1110, 2001.

TAIZ, L.; ZEIGER, E. Fisiologia vegetal. 5. ed. Porto Alegre: Artmed, 2013. 918 p.
TORRES, S. B.; VIEIRA, E. L.; MARCOS FILHO, J. Efeitos do estresse hídrico na germinação e no desenvolvimento de plântulas de pepino. Revista Brasileira de Sementes, Londrina, v. 21, n. 2, p. 59-63, 1999.

VILLELA, F. A.; DONI FILHO, L. D.; SIQUEIRA, E. L. Tabela de potencial osmótico em função da concentração de polietileno glicol 6000 e da temperatura. Pesquisa Agropecuária Brasileira, Brasília, v. 26, n. 2, p. 19571968, 1991. 
